\section{ROLE OF DIAZOXIDE THERAPY IN SMALL FOR GESTATIONAL AGE INFANTS WITH PROLONGED HYPERINSULINEMIC HYPOGLYCEMIA}

Sandra Jaya-Bodestyne, Victor Samuel Rajadurai, Mohanambal Arumugham, Mei Chien Chua, Fabian Yap, Suresh Chandran. Singapore

\subsection{6/bmjpo-2021-RCPCH.85}

Background Small-for-gestational-age (SGA) infants are at-risk of hyperinsulinemic hypoglycemia $(\mathrm{HH})$, requiring high glucose infusion rates (GIR) to maintain euglycemia.

Objectives To compare the outcomes of SGA infants treated with diazoxide (DZX) versus watchful waiting (WW) with high GIR and feeds in the management of $\mathrm{HH}$.

Methods This observational study was conducted from September 2014 to September 2020. SGA infants with HH (GIR $>10 \mathrm{mg} / \mathrm{kg} / \mathrm{min}$, plasma glucose level $<3.0 \mathrm{mmol} / \mathrm{l}$ with detectable insulin) were identified. Data on sex, gestational age (GA), birth weight (BW), age at presentation, symptoms, critical investigations, GIR, dose and duration of DZX treatment, and outcomes were analyzed.

Results 56 SGA infants were identified - 27 DZX and 29 WW, male infants being 56\% and 62\% respectively. Mean GA were 36.4(31-40) for DZX and 36(30-39) weeks for WW. BW were $1942 \pm 356$ vs $1873 \pm 498$ gm respectively. $96.4 \%$ of infants presented on day 1 of life. More DZX treated infants had symptomatic HH (DZX, 22\% vs WW, 7\%; p=0.227). Paired glucose/insulin levels were $2.37 \pm 0.47 \mathrm{mmol} / \mathrm{L} / 16.39$ $\pm 27.4 \mathrm{mU} / \mathrm{L}$ in DZX and $2.45 \pm 0.65 \mathrm{mmol} / \mathrm{L} / 8.65 \pm 11.3 \mathrm{mU} /$ L in WW cohort $(p=0.196)$. Maximum GIR in DZX cohort was $14.8 \pm 4.3$ vs $13.1 \pm 3.2 \mathrm{mg} / \mathrm{kg} / \mathrm{min}$ in WW $(p=0.097)$. Mean day of DZX initiation was $12.9 \pm 8.2$ days with an average treatment duration of 65 days and the maximum dose was $4.6 \pm 2.2 \mathrm{mg} / \mathrm{kg} /$ day. Duration of central venous line, day of resolution, and day to discharge were not statistically different between the two cohorts. However, infants who had DZX initiation $<10 \mathrm{~d}$ vs $>10 \mathrm{~d}$ of life had earlier resolution of $\mathrm{HH}(\mathrm{p}=0.013)$.

Conclusions Spontaneous resolution does occur in SGA infants with high GIR and feeds. DZX being a $\mathrm{K}_{\mathrm{ATP}}$ channel agonist, its use should be restricted to symptomatic infants requiring persistently high GIR, especially in early days of life, as the DZX related long-term outcome is unclear. Duration of intensive care treatment for $\mathrm{HH}$ was not statistically different between the two cohorts.

\section{THE IMPACT OF CORONAVIRUS ON SAFEGUARDING REFERRALS TO A TERTIARY UK HOSPITAL}

V Timmis, F Payne, L Alison, E Asumang. UK

\subsection{6/bmjpo-2021-RCPCH.86}

Background Have coronavirus restrictions resulted in missed child protection concerns.

Objectives To evaluate the:

1. impact of coronavirus, and the public health measures taken to address it, on child protection referrals.

2. effect on child protection referrals following the re-opening of educational services.

Methods A retrospective review of patient notes was carried out for all safeguarding medicals to a tertiary dedicated UK children's hospital between:
- April and June 2020 (peak lockdown)

- April and June 2019

- September to November 2020 (as schools and childcare settings re-opened to all children)

Data was entered into an Excel spreadsheet and quantitative analysis undertaken.

Results

- The total numbers of safeguarding referrals were similar across all 3 time periods.

- Physical abuse was the most common category for referral throughout. There was a higher proportion of neglect in both 2020 data sets compared to 2019.

- Children were previously known to social care at the time of their referral in $38 \%$ of cases in 2019 compared to $60 \%$ of cases in both 2020 data sets.

- Most children were managed as outpatients: 84\% in AprilJune 2019, 76\% in April- June 2020 and 92\% of SeptemberNovember 2020.

- In April - June 2020 20\% children required ongoing medical care or intensive care in comparison to 10\% of cases in 2019.

- Abuse was confirmed or suspected in $54-55 \%$ of cases across all 3 time periods.

Conclusions Concerns about children not being referred for safeguarding medicals are not supported from this data. In contrast, other UK centres have reported their referrals dropped by a third. [i] ${ }^{\text {,ii] }}$

During the lockdown period more children required hospitalisation including to intensive care compared to 2019, reflecting more significant injury.

The 2020 data sets had a higher proportion of neglect cases, potentially reflecting the increased pressure coronavirus had put on already vulnerable families.[iii]

During lockdown educational settings identified safeguarding concerns in only $6 \%$ of cases, potentially explained by extensive educational closures. $15 \%$ of referrals in SeptemberNovember 2020 data were identified by education, not supporting the concern of a spike in referrals as schools re-open. This has been found elsewhere also. [iv]

\begin{tabular}{lcccccc}
\multicolumn{2}{l}{ Abstract } & $\mathbf{1 5 2}$ Table 1 & & & & \\
\hline Time period & Total referrals & Physical & Neglect & Emotional & CSA & Forensic \\
\hline 2019 & 90 & $51 \%$ & $7 \%$ & 0 & $23 \%$ & $19 \%$ \\
$\begin{array}{l}\text { April - June } \\
2020\end{array}$ & 90 & $49 \%$ & $14 \%$ & 0 & $25 \%$ & $12 \%$ \\
$\begin{array}{l}\text { April- June } \\
2020\end{array}$ & 89 & $51 \%$ & $18 \%$ & $2 \%$ & $18 \%$ & $11 \%$ \\
Sept- Nov & & & & & & \\
\hline
\end{tabular}

Abstract 152 Table 2

\begin{tabular}{lllllll}
\hline Time period & Social care & Police & Hospital staff & School & GP & Other \\
\hline 2019 & $14 \%$ & $28 \%$ & $20 \%$ & $27 \%$ & $8 \%$ & $3 \%$ \\
April- June & $35 \%$ & $23 \%$ & $24 \%$ & $6 \%$ & $4 \%$ & $8 \%$ \\
2020 & & & & & & \\
$\begin{array}{l}\text { Sept- Nov } \\
2020\end{array}$ & $50 \%$ & $16 \%$ & $13 \%$ & $15 \%$ & $6 \%$ & $0 \%$ \\
\hline
\end{tabular}

